\title{
Sobre La Canción de Rachel, Novela-Testimonio
}

En el efervescente ambiente literario cubano actual coexisten dos generaciones: la del 24 (nacidos entre 1894 y 1924) cuyo grupo caracterizador lo constituyen las vanguardias y posvanguardias y la generación del 54 (nacidos entre 1925 y 1954) que se identifica con el reformismo técnico y lingüistico actuales. Cada generación puede dividirse a su vez en promociones. Hoy nos interesa la generación del 54 a la que se ha llamado "revolucionaria" y especialmente su segunda promoción (nacidos entre 1939 y 1954), ${ }^{1}$ que se lanza a la vida literaria cuando se acelera en la Isla la búsqueda de una literatura que refleje cabalmente el sentimiento de la nueva Cuba. Podemos decir que los afanes caracterizadores de esta segunda promoción son la búsqueda de la identidad nacional y la ruptura total con el colonialismo, preocupaciones que han motivado una revaloración de la historia y la cultura cubanas para presentar los acontecimientos isleños desde diversos ángulos. $Y$ de ahǐ el interés en rescatar para la posteridad el impacto de individuos anónimos - hacer la historia de los hasta hoy marginados por la historia- en el proceso cultural cubano. Estas inquietudes han dado lugar a obras como Los años duros (1966) de Jesús Díaz (n. 1941), en las que el autor narra en lenguaje sencillo momentos de la lucha revolucionaria signados por la participación de individuos anónimos, y al auge de la novela testimonial cultivada por el poeta y narrador Miguel Barnet (n. 1940), autor de Biografía de un cimarrón (1967) y La canción de Rachel (1969). Este joven polïgrafo que se define a sî mismo como artista sociológico, busca una expresión auténtica interpretando a fondo la historia para llegar a la verdadera "literatura de fundación" postulada por Octavio Paz. 
Para Barnet, el vehículo de expresión adecuado para manifestar sus conceptos sobre la narrativa es la novela-testimonio, por proponer ella un "desentrañamiento de la realidad, tomando los hechos principales, los que más han afectado la sensibilidad de un pueblo" que en boca de uno de sus protagonistas adquieren nuevo sentido histórico. ${ }^{2}$ Esta definición de la novela-testimonio apunta hacia un discurso polifónico, donde el creador, al aprehender la época a través de un protagonista, lo presenta independientemente y no como objeto de su visión artística. En contrapunto, otros personajes ofrecen una imagen diferente del mismo período temporal. Estas diversas voces narrativas actúan como fuerzas centripetas y contribuyen a ofrecer una visión dialéctica de la realidad. 3 Por tanto, la verdadera novela-testimonio suprime el punto de vista del narrador omnisciente y logra la sintesis autor-protagonista que les permite exclamar al unísono "Yo soy la época." 4

Los protagonistas de las novelas de Barnet son un negro y una mujer. En Biografía de un cimarrón, el anciano Esteban Montejo nos da la intrahistoria de Cuba vista en tres momentos de su vida: esclavitud, cimarronería y libertad. En La canción de Rachel una melancólica, sensual y contradictoria cupletista del teatro Alhambra cuenta su vida. En su relato notamos la actitud decadente de la primera república y vemos desde dentro la historia de Cuba ahora iluminada por esta voz femenina, trágica víctima de las fuerzas que ha intentado vencer con su cuerpo y su ilusión. La selección de Barnet no ha sido casual. Esteban y Rachel representan a dos grupos marginados, cuyo status en la sociedad cubana ha preocupado al gobierno revolucionario desde su ascenso al poder. En un temprano discurso del 6 de febrero de 1959, Fidel Castro, consciente de la labor reestructuradora a emprender por el gobierno revolucionario, llama la atención sobre la tragedia que confrontan dos sectores injustamente discriminados: la mujer y el negro. Ahï sagazmente nota que la discriminación sexual subyacente en la sociedad cubana es más fuerte que la racial, precisamente porque se la ignora. 5

La protagonista de La canción de Rachel tiene poco en común con Ana Betancourt, Mariana Grajales y Rosa la Bayamesa. Como ellas es mujer; pero Rachel pertenece a un grupo doblemente marginado por su sexo y por su profesión. Fácilmente acepta el lugar que le ha señalado la sociedad hasta llegar a convertirse en una "sin historia." Vive su vida en función de otros, tocada por fuerzas incomprensibles que ella ingenuamente cree controlar. Para Miguel Barnet, Rachel representa su época y sintetiza el mundo de coristas del desa- 
parecido Teatro Alhambra, tan importante para conocer los avatares políticos de la Isla en sus primeras décadas de vida republicana: 6 Rachel, "por su condición de artista, tenía vínculos en casi todos los estratos de la población." Además, ella ha sido testigo de acontecimientos que afectan la vida nacional y los interpreta revelando recónditas motivaciones y difuminados contornos. 7

¿Tiene Rachel algo de su homónima, la notoriamente asesinada prostituta francesa, que junto con Nena "Capitolio" -conocida amante de los residentes de esa casa- marcó la década del treinta en Cuba? 8 Barnet confiesa que encontró a Rachel "en múltiples vedettes retiradas, en viejas cocottes de La Habana de los años veinte, en Petit Bertha, envuelta en una ilusión de creyones de labios, amante de Yarini, en la memoria de Luz Gil, en la inigualable Amalia, melancólica y soberbia; la única flapper de todas, y sobre todo en la psicología de mucha mujer cubana."9 La canción de Rachel va más allá de la biografía literaria. Componen este personaje femenino girones de muchas vidas estructurados por el autor para darnos una imagen verídica de las limitaciones históricas y socio-culturales opuestas al desarrollo de una mujer, de los cubanos y de la Isla. La cuidadosa elaboración de fuentes, el uso de la técnica contrapuntỉstica y de un decantado lenguaje, esencia del dialecto cubano pero alejado de la mera reproducción folklorista, resultan en una obra trabajada, verdadero "continuum" cronológico y estructural de Biografia de un cimarrón. 10

La canción de Rachel comienza con la República y termina con la dictadura machadista y la desaparición del teatro para hombres solos: Alhambra. ${ }^{11} \mathrm{La}$ niñez de Rachel coincidé con la llegada del tranvïa eléctrico a La Habana y su madurez con la presidencia de José Miguel Gómez (1909-1913), caracterizada por el popular slogan de “Tiburón se baña, pero salpica." A su regreso de Europa, la aparición del cometa Halley (1910) y la muerte de Alberto Yarini, el "gigolo" más popular que ha dado Cuba, son los acontecimientos que conmueven a la protagonista a la vez que marcan ese período histórico. Rachel lamenta el asesinato de Yarini porque es hombre, joven y hermoso. Y no comprende por qué critican su modo de vida. Los más concurridos funerales de Cuba - del político ortodoxo Raúl Chibás, de la popular artista Rita Montaner y del aplaudido "bárbaro del ritmo," Beny Moré- no han superado a los de Yarini, hombre cuyas mayores virtudes eran su apariencia y el no darse fácilmente. ${ }^{12}$ Sin embargo, es la "guerrita del 12," "la bulla racista," la que nos permite auscultar este período histórico cuyo acendrado prejuicio 
marginó a un grupo de cubanos sin cuya participación en las luchas libertarias no se hubiera logrado la independencia de la Isla. Cuando Rachel nos ofrece sus chocantes opiniones sobre los acontecimientos, se convierte en denominador de su época. La instauración de la república de "charol" con su bandera de franjas azules y triángulo rojo donde figuraría un potro negro y no la estrella "solitaria" de Narciso López; el supuesto arribo de "cow boys" norteamericanos que enlazarìnan a los disidentes como reses bravas; 13 el mucho ron con que se hizo la guerra y el mucho soborno necesario para concluirla, exigen una respuesta ( $\mathrm{p}$. 35). Y ella nos llega contrapuntisticamente por boca de Esteban Montejo: “ ¿. . . cuándo en este país se elevó al pueblo un programa más democrático que el de Los Independientes de Color, cuándo aquil se luchó a brazo partido por lograr beneficios para los negros, que salíamos de la guerra descalzos y harapientos ...?" (p. 59).14 Contradictoriamente, Mariana Grajales es la santa patrona de Rachel a quien implora en momentos claves (p. 71). La herencia africana de la Isla es, como la madre de Antonio Maceo en la vida de Rachel, esencial en el desarrollo de Cuba, a cuya cultura aporta carácter definitorio.

El apogeo de Rachel en el Alhambra coincide con la visita de Caruso a Cuba y los primeros años de la dictadura machadista. En esta época se arraiga el sainete y Rachel, guiada por el cómico Acebal, lleva tipos criollos a las tablas. Aunque Rachel se juzga "demócrata" y "liberal" en asuntos raciales, sus comentarios - "con todo y su color era educado...."; "cada uno en su justo y humano lugar, sin mescolanzas innecesarias" (p. 99) - indican el acendrado prejuicio imperante en los diversos sectores de la sociedad cubana.

La cupletista del Alhambra hace un acertado paralelo entre la política cubana y el cachumbambé: "un saltico para arriba y otro para abajo." Pero la tragedia no son los saltos, sino los saltarines. Mezclarse en política es "ensuciarse;" pero quien no lo hace "tiene que pedir el agua por señas" (p. 94). En su medio Rachel puede observar los al tibajos políticos en las abandonadas coristas cuyos protectores han perdido las prevendas. Rachel intuitivamente comprende que en la Cuba de entonces la política tiene una función accesoria, pues no presenta soluciones a los problemas del país, y por eso usa estos descalabros para hacer reír a su público. El traje de bandera cubana que Rachel compra en su itinerante recorrido por el interior de la Isla con el circo "Las maravillas de Austria" evoca el destino de Cuba. La artista se disfraza con la bandera para atraer clientes; los políticos encubren sus actos con sagrados principios que no estorban 
su enriquecimiento personal ni la aceptación de honerosas concesiones. El desfile de Rachel por las calles de Santa Clara parodia la comparsa política cubana bien ejemplificada por la clásica "chambelona" de Menocal.

Rachel vive la ilusión de su "triunfo" como Cuba vive el espejismo de ser república independiente. Ella, como su madre, cree haber hecho "con su cuerpo lo que le vino en gana" (p. 13). Pero este control está limitado por la necesidad: a los nueve años tecleaba el piano y bailaba la rumba; a los trece deja la escuela obligada por el hambre y se convierte en la primera figura del Teatro Tívoli. Alli conoce a Eusebio, joven aristócrata que se enamora perdidamente de ella; siguen la oposición familiar al matrimonio, el suicidio de Eusebio -"la única pasión pura de mi vida" (p. 18)- y un embarazo interrumpido a los seis meses. El dueño del circo "Las maravillas de Austria," Adolfito y Federico, son meros escalones en la carrera artística de Rachel. Con el declinar del Alhambra llegan la tabla salvadora de un fiscal de Matanzas, la clásica mensualidad $(\$ 1,500.00)$, seis casas de alquiler y una de prostitución. Rachel cree haber sido lo que su ilusión le pidió (p. 17). Pero acaso intuye que vive el espejismo de su época y de sus triunfos forjados con girones de sì misma y de su urgencia por sobrevivir en un medio hostil, cuando exclama: "Jamás me ha gustado quitarle a nadie su ilusión" (p. 17). Como su época, carece de escrúpulos y conserva el deseo de triunfar y de realizarse a toda costa. Su trayectoria expone y denuncia, pero también resalta el espíritu indomable de esta mujer, representativa, como Esteban Montejo, de otro grupo preterido en la sociedad cubana. Conocer a Rachel es ver con luz nueva un doloroso periodo de la historia cubana. Y sólo conociendo esas raíces y esa problemática hallaremos el camino para la mujer y el hombre nuevos en la nueva sociedad. Cantamos el réquiem por Rachel y el pasado que ella representa, buscando con Martì "la esencia y realidad de un pails republicano nuestro, sin miedo canijo de unos a la expresión saludable de todas las ideas y el empleo honrado de todas las energías."15

The City College, CUNY

RAQUEL CHANG-RODRIGUEZ

\section{NOTAS}

1. Baso esta periodización en José Juan Arrom, Esquema generacional de las letras hispanoamericanas (Bogotá: Instituto Caro y Cuervo, 1963). Las fechas de la división en promociones proviene de un manuscrito inédito que el Profesor Arrom me ha peritido consultar y cito con su permiso. 
2. Miguel Barnet, "La novela testimonio: socio-literatura," Apéndice a La canción de Rachel (Barcelona: Esleta, 1970), p. 135.

3. Para una buena discusión de lo que es novela polifónica, véase, Jorge Schwartz, "Don Segundo Sombra: una novela monológica," Revista Iberoamericana, 42, Nos. 96-97, pp. 427-446.

4. Barnet, p. 137.

5. Citado en Margaret Randall, Mujeres en la revolución (México: Siglo Veintiuno Editores, S. A., 1972), p. 3.

6. Cada semana el Teatro Alhambra presentaba una obra basada en temas de actualidad. Alcanzaron gran popularidad "Entre cubanos no vamos a andar con boberías," de Gustavo Robreño (1873-1957) y "La danza de los millones" de Federico Villoch. Desafortunadamente ninguna de estas obras ha sido impresa. Cabe notar que muchas de las piezas presentadas en el Alhambra, "después de un proceso de adecentamiento," pasaban al Teatro Nacional o al Payret con asistencia del público general. Véanse, José Juan Arrom, Historia de la literatura dramática cubana (New Haven: Yale University Press, 1944), pp. 89-90; y Max Henriquez Ureña, Panorama histórico de la literatura cubana, II (New York, Las Americas Publishing Co., 1963), pp. 344-345.

7. Rogelio Martinnez Fure, "Lo que me contaron de Rachel (entrevista con Miguel Barnet)," Gaceta de Cuba, No. 76 (septiembre de 1969), p. 18.

8. Ramón López, "El danzón de Rachel," Casa de las Américas, No. 57 (1969), p. 122.

9. Barnet, p. 135.

10. Angel Luis Fernández Guerra, "Cimarrón y Rachel, un continuum," Unión, No. 4 (diciembre de 1970), pp. 161-167.

11. En 1935 se derrumbó la parte delantera del teatro causando heridos y muertos. Este accidente determinó la clausura de la sala.

12. Miguel Barnet, La canción de Rachel (Barcelona: Esleta, 1970), p. 37. Citamos por esta edición.

13. El 25 de mayo de 1912, el gobierno de los Estados Unidos avisó al Secretario de Estado cubano que la infantería de marina desembarcaría en Cuba si el gobierno no podia garantizar la vida y propiedades norteamericanas. La nota indica, irónicamente, que este hecho no se deberia considerar una "intervención." El Presidente Gómez protestó notando que si habìa desembarco tenĩa que ser con el previo acuerdo del gobierno cubano. Una nota del 29 de mayo de 1912 rechaza la idea del previo acuerdo, y el 31 de mayo de 1912 los "marines" desembarcaron en Daiquirí, Oriente. Véase, Charles E. Chapman, $A$ History of the Cuban Republic (New York: The MacMillan Co., 1927), pp. 308-312.

14. El Partido Independentista de Color se fundó en 1907; surgió mayormente por la disatisfacción de los negros cubanos con la política del Partido Liberal y por su desconfianza del gobierno provisional norteamericano. Pronto se convirtió en un movimiento de reforma social con células en diversas provincias. Véanse, Allan Reed Millett, The Politics of Intervention (Columbus: Ohio State University Press, 1968), pp. 177-178; y Rafael Fermoselle Política y color en Cuba (Montevideo: Ediciones Geminis, 1974).

15. Obras completas (La Habana, Lex, 1946), I, p. 701. 